\title{
Sudden unexpected death and covert homicide in infancy
}

\author{
S Levene, C J Bacon
}

Arch Dis Child 2004;89:443-447. doi: 10.1136/adc.2003.036202

It is impossible to be certain, but it is estimated that each year in England and Wales there may be about 30-40 infant deaths from covert homicide, which represents about $10 \%$ of the current annual total of sudden unexpected deaths in infancy. This paper reviews the features that have been suggested as possible indicators of covert homicide, describes the difficulties in its identification and the need for better evidence, and emphasises the importance of thorough medical investigation of all sudden infant deaths.

See end of article for authors' affiliations ......................

Correspondence to: Dr C J Bacon, Foundation for the Study of Infant Deaths, Artillery House, 11-19 Artillery Row, London SWIP IRT, UK; fsid@sids.org.uk

Accepted

17 December 2003
I $\mathrm{n}$ England and Wales there are about 30 convictions a year for infant homicide, ${ }^{1}$ which means that we are more vulnerable to homicide in the first year of life than at any other age. ${ }^{2}$ Homicide is officially defined as comprising murder, manslaughter, and infanticide. Infanticide as a legal term is specific for the killing of an infant aged less than 12 months by a mother whose mind is disturbed from the effects of childbirth or lactation; it is comparatively rare, with fewer than 10 cases recorded each year. The killing of a child by a parent may also be called "filicide", but this term does not constitute a separate legal category.

The convictions mentioned above are for homicide that is recognised and confirmed by a criminal court. In contrast, this paper is about homicide that goes unrecognised and where the death may mistakenly be attributed to another cause such as sudden infant death syndrome. Such deaths may be described as "deaths arising from unrecognised maltreatment", "unrecognised fatal child abuse", or "covert homicides".

\section{HISTORICAL BACKGROUND}

Sudden infant death syndrome (SIDS) or an equivalent term was officially accepted as a registrable cause of death in England and Wales in 1971. A sudden and unexpected death of an infant (SUDI) could then be registered as SIDS if the pathologist who did the postmortem examination could find no specific cause for the death but was confident that it was natural. From the outset there were occasional suggestions that some deaths attributed to SIDS might in fact have resulted from maltreatment, but this notion did not gain more general credence until the 1980s when Emery, drawing on his great experience of postmortem examinations and interviews with parents, gave it his authoritative support. ${ }^{3}$ In recent years the issue has come to the fore because the marked decrease in the total number of SUDI and SIDS has made the few that result from maltreatment more prominent.
Figure 1 shows how, as total SIDS has fallen, on the assumption that the number of covert infant homicides is fairly steady, their proportion of the total will have risen considerably. The interface between child abuse and sudden infant death has been reviewed by Hobbs and Wynne. ${ }^{4}$

\section{FREQUENCY OF COVERT HOMICIDE}

It is impossible to be certain of the frequency of covert homicide among sudden infant deaths. By definition covert homicide is hard to identify, either from the history, because the perpetrator acts in secret and conceals what has happened, or from the postmortem examination, because there may be no diagnostic signs. In addition, the existence of a category of unexpected and unexplained deaths that result from natural causes, namely sudden infant death syndrome, offers an acceptable alternative explanation. Emery eventually estimated that between 10\% and $20 \%$ of SUDI might result from filicide (the term he preferred), with variation from place to place. ${ }^{5}$ At the time he was writing there were about 1000 SUDI a year in England and Wales, so that if his estimate was correct and generally applicable they would have included between 100 and 200 cases of covert homicide. More recent assessments suggest a lower figure (see below).

The most accurate estimates are likely to come from studies that are large scale and population based, and that consider the question systematically. The only published survey that meets these criteria is the study of sudden unexpected deaths in infancy carried out in five English health regions as part of the Confidential Enquiry into Stillbirths and Deaths in Infancy from 1993 to 1996 (CESDI SUDI study). ${ }^{6}$ This study included all post-perinatal sudden unexpected deaths from a population of 13 million that had nearly 500000 births during the period. Twenty two deaths were not studied in detail because they were subject to police investigation; all or most of these 22 deaths are likely to have ended up in the figures for recognised homicide. The remaining 417 deaths, of which 346 were attributed to SIDS and 71 to a specific cause, were subject to a case-control study and to confidential enquiry. After scrutinising all available details, including personal and family histories, full circumstances of each death, and reports of extensive postmortem examinations, expert panels concluded that maltreatment was the main cause of death in $6.4 \%$ of the cases

Abbreviations: ALTE, apparent life threatening event; FII, fabricated or induced illness by carers; SIDS, sudden infant death syndrome; SUDI, sudden and unexpected death of an infant 


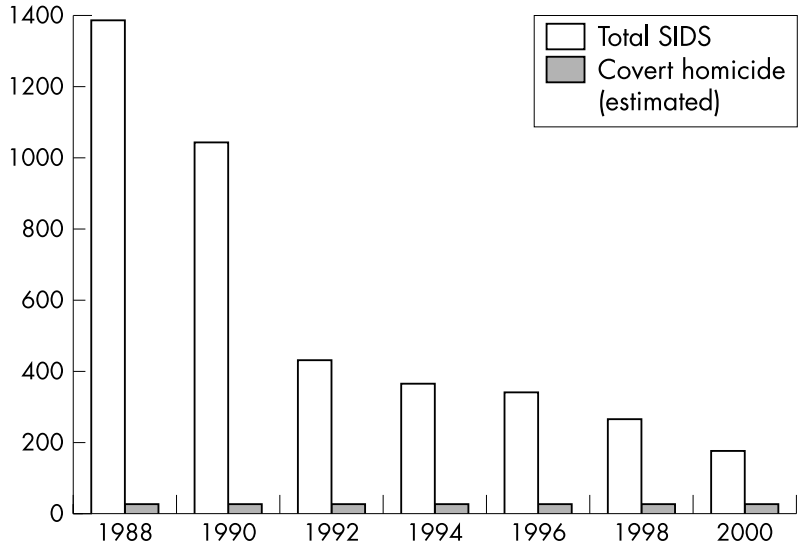

Figure 1 Covert homicide as a proportion of SIDS.

categorised as SIDS and in $6.0 \%$ of those for which a specific cause had been attributed. Maltreatment was cited as a secondary or alternative cause of death in $8.1 \%$ and $5.6 \%$ of cases respectively. It should be noted that "maltreatment" was defined widely, and encompassed a range from deliberate smothering to negligence and poor care.

Although the confidential enquiry component of the CESDI SUDI study probably provides the best estimate of covert homicide yet available, its judgements are ultimately subjective and thus open to error. On the crude assumption that all the cases attributed primarily to maltreatment and half the cases attributed secondarily or alternatively to maltreatment resulted from covert homicide, the proportion of covert homicides among SIDS at that time would be around $10 \%$. The mean annual incidence of post-perinatal SIDS in England and Wales during the study was 343. National extrapolation from the proportion suggested by the CESDI SUDI study would therefore give a figure of 34 covert homicides a year among deaths registered as SIDS, and, by a similar calculation, about six more among SUDI attributed to other causes. This would give a total of about 40 covert homicides a year among SUDI in England and Wales, which is considerably below Emery's estimate.

As Emery suggested, it is likely that the incidence of covert homicide varies from place to place, according to social conditions. In the city of Leeds, for example, Hobbs and colleagues $^{7}$ found major issues of abuse or neglect in 10 of 37 unexpected infant deaths occurring in 1991-92, while Stanton, ${ }^{8}$ studying 69 families in a more rural part of the same county who had unexpected infant deaths between 1982 and 2000, concluded that only four deaths (two each from two families) resulted from maltreatment.

The proportion of covert homicides will of course vary with the total number of SUDI. The incidence of SIDS continues to fall, only 180 cases being registered in England and Wales in the year 2000. This might suggest that the proportion of covert homicides among SIDS has risen correspondingly. On the other hand an increasing number of deaths that would formerly have been classified as SIDS are now registered as "unascertained", in some but not all instances because they are regarded as suspicious." And a recent upward trend in figures for convicted homicide in infancy ${ }^{1}$ suggests that more cases are now being recognised by the police. It is not possible to be certain how these factors balance out, but it seems reasonable to suppose that the proportion of covert homicides among deaths registered as SIDS remains at about $10 \%$, while the proportion among deaths registered as "unascertained" is likely to be somewhat higher. The total we estimate for covert homicide in infancy, around 40 deaths a year, is thus a little higher than that for convicted homicide (though it should be noted that the estimate for covert homicide based on the CESDI SUDI study excludes deaths in the first week, whereas these are included in the Home Office figures for convicted homicide). If more than half of all infant homicides are not being recognised it is to be expected that the police should wish to look closely at every SUDI.

\section{MODE OF DEATH}

The mode of homicide in infancy can often be identified from the circumstances of the death or from external examination of the body. If no signs are immediately obvious, homicide may sometimes be revealed by a thorough postmortem examination that includes a full range of ancillary tests. Poisoning, for example, can be identified by the relevant toxicological assays, while fatal shaking can be recognised from microscopic examination of the brain. If the appropriate tests are not done, however, the true mode of death may not be revealed. Or sometimes signs of maltreatment may be detected but wrongly attributed to another cause, for example intracranial haemorrhage to accidental trauma or broken ribs to resuscitation. The term "covert homicide" may thus be applied either to cases where a potentially identifiable homicidal cause of death was missed or misdiagnosed, or to cases where homicide cannot, in the present state of knowledge, be identified even by the fullest investigation. The best known mode of homicide in the last category is suffocation. Suffocation may leave no external signs and no clear postmortem evidence. ${ }^{10}$ The significance of intraalveolar haemorrhage and siderophages is still subject to debate. ${ }^{11}$ We know that mothers do sometimes suffocate their babies because a number have made very credible confessions, ${ }^{12}{ }^{13}$ while others have been witnessed by video surveillance. ${ }^{14} 15$

\section{CHARACTERISTICS OF COVERT HOMICIDE}

Because covert homicide is infrequent and hard to identify, there have been no large scale and controlled studies of its characteristics. All that exists are anecdotal reports of comparatively small numbers of cases, and their conclusions are sometimes contradictory. The largest series is that of Meadow, ${ }^{16}$ who reported on 81 deaths from 51 families occurring over a period of 18 years, all of which had originally been ascribed to natural causes (including 42 cases of SIDS) but were subsequently deemed by a court to have resulted from homicide by a parent (though some of these cases may now be subject to review). Meadow's paper is widely quoted and has been very influential. However it has two important limitations. Firstly, the cases were very highly selected, consisting of referrals to a renowned specialist during a period when there were over 20000 SIDS deaths in England and Wales. The cases of covert homicide reported may not therefore be representative, and, as the author acknowledges, their number does not provide evidence on the frequency of the problem. Secondly, the paper does not set out to give control data, and the features presented as characteristic of unnatural death need to be evaluated in the light of control data from elsewhere.

\section{Age range}

The typical age distribution for SIDS shows a few deaths in the first four weeks of life, a peak at two to three months, then a fairly rapid decline so that $80 \%$ of cases have occurred before six months. ${ }^{17}$ Deaths over the age of 12 months are occasionally attributed to SIDS but this is very uncommon. The peak age for death in Meadow's 81 cases was 5-6 months, considerably older than the norm for SIDS, while nine $(11 \%)$ were more than a year old. Southall et al, reporting on 30 cases of deliberate suffocation detected by covert video surveillance, ${ }^{18}$ found a median age for the onset 
of symptoms, corrected for expected date of delivery, of 3.6 months (range $0.1-32.5$ months), in contrast with a corrected median age of 0.3 months for 46 infants with apnoeic attacks from natural causes.

Thus it appears that in younger babies age does not help discriminate between natural and unnatural death, but unexplained natural death is increasingly less common after the age of 6 months.

\section{Time of death}

The typical sequence of events in SIDS is for the baby to be put to bed well or with a mild illness and to be found dead when next seen by the mother, either later that night or next morning. Thus $270(83 \%)$ of the 325 SIDS babies in the CESDI SUDI study died at night. In contrast $55(76 \%)$ of the 72 of Meadow's cases for whom this information was available were found moribund or dead during the day between 11 am and $10 \mathrm{pm}$. However a survey of 355 sudden infant deaths carried out in 1980-81 found that about half died during the day. ${ }^{19}$ Although it is impossible to be certain that no cases of covert homicide were included in this survey, it appears that time of death cannot be regarded as a strong discriminator.

\section{Previous unexplained infant death}

In $24(48 \%)$ of Meadow's 51 families more than one child died: 18 families had two deaths, five had three, and one family had four deaths. In Southall's families 12 of 41 previous siblings had died, 11 deaths being originally attributed to SIDS and one to gastroenteritis; it was subsequently concluded that nine of these 12 deaths were in fact caused by abuse. There have been a number of other reports in which a mother who at first received sympathy for losing successive children to SIDS was subsequently convicted for their murder. It therefore appears that there is a pathological type of mothering, fortunately uncommon, that can bring about the death of more than one baby in the family. This has led to the maxim first proposed in 1989 by the American forensic pathologists Dimaio and Dimaio: "While a second SIDS death from a mother is improbable, it is possible and she should be given the benefit of the doubt. A third case, in our opinion, is not possible and is a case of homicide" ${ }^{20}$ This yardstick is too simplistic because there are a number of familial medical disorders that may kill more than one child without being diagnosed. Examples include medium chain acyl coA dehydrogenase deficiency ${ }^{21}$ and other defects of fatty acid oxidation, ${ }^{22}$ mitochondrial respiratory chain disorders, ${ }^{23}$ the long Q-T syndrome, ${ }^{24}$ central hypoventilation syndrome, ${ }^{25}{ }^{26}$ and congenital narrowing of the upper airway. ${ }^{27}$ Any assessment of repeat deaths must therefore include a thorough search for known familial disorders-and it is possible that there are others yet unrecognised.

In addition, the risk of SIDS varies widely with the circumstances of the family and their child care practices. The presence of several risk factors, such as poverty, a young mother, and heavy smoking, renders a family much more likely to lose a second baby to SIDS than the overall incidence might suggest. ${ }^{6}$ There might also be genetic factors, falling short of recognised defects, that predispose to SIDS. It is not valid to estimate the odds for a second case of SIDS in a particular family by squaring the odds for a first case in that group, ${ }^{28}$ because each family has its own unique blend of genetic and environmental factors that determines its susceptibility.

Most authors have reported the risk for a second SIDS death to be between about two and six times that for a first death. ${ }^{29-31}$ The largest population based study is that of Oyen et al, who analysed deaths among the babies of 352475 Norwegian mothers who had first and second single births between 1967 and 1988. ${ }^{32}$ SIDS mortality among second infants was $11.7 / 1000$ if the first baby had died from SIDS, in contrast to $2.0 / 1000$ if the first baby survived, giving a relative risk of 5.9 (95\% CI 2.5 to 14.7 ). If the first baby had died from SIDS there was also a threefold increase in the risk of the second baby dying from a cause other than SIDS. However it is not clear how rigorously the deaths in this and other studies were investigated to exclude either familial disorder or homicide.

Data on the recurrence of SIDS can also be found in the report on the first 5000 babies enrolled in the Care of the Next Infant (CONI) scheme between 1988 and 1997. ${ }^{33}$ This is a voluntary scheme, available in most parts of England and Wales, designed to support families who have a new baby, having lost a previous baby by SIDS. Of 4182 families who chose to enrol in the scheme, 93 had had more than one previous infant death registered as SIDS. This gives a recurrence rate prior to enrolment of $22.2 / 1000$, which is well above the overall incidence of SIDS for the period in question and shows the unusual vulnerability of these families. It is possible that some of these deaths, which could not be adequately examined retrospectively, may have been incorrectly diagnosed and may have included cases of covert homicide. There were 44 deaths of babies while on the CONI scheme, for 33 of which permission was obtained from the parents and general practitioner for full investigation and confidential inquiry. Eight of these 33 deaths were classified as SIDS, which gives a recurrence rate of 1.9/1000, about twice the incidence of SIDS for the period. The difference between the recurrence rates for the periods before and during the scheme is thought to result from a combination of the falling incidence of SIDS, the preventative effect of the scheme and greater diagnostic accuracy.

The CONI data also shed some light on the proportion of recurrent deaths that might result from homicide. Among the 33 recurrent deaths that were adequately investigated, in five there was a conviction for homicide, two more were attributed to non-accidental injury (though there was no prosecution), and in three more there was suspicion. In this series of recurrent deaths, therefore, $30 \%$ were thought to have been definitely or possibly the result of homicide. Subsequent analysis of an extended series of recurrent deaths in the CONI programme found a smaller proportion that were unnatural (RG Carpenter, personal communication). It is possible that the self-selectivity of the sample may have biased this figure downwards. Allowing for this, the proportion is compatible with those found in earlier studies of recurrent infant deaths by Emery ${ }^{34}$ and by Wolkind and colleagues, ${ }^{35}$ the former concluding that five of twelve (42\%) and the latter that 31 of $57(55 \%)$ recurrences resulted from homicide.

Thus a previous unexplained infant death in a family should always raise serious concern, but this must be balanced by awareness that second and subsequent deaths can also arise from natural causes.

\section{Previous unexplained illness}

In 58 of the 75 babies (77\%) of Meadow's cases for whom a full history was available there were reports of previous unusual or unexplained episodes, such as apnoea, cyanosis, collapse, or seizures. In 27 babies (36\%) these episodes were deemed to constitute an apparent life threatening event (ALTE). It was recognised in the 1970s that sudden infant deaths might sometimes be preceded by a number of episodes of sudden collapse, in which typically the baby was found at home cyanosed and apparently moribund, was taken urgently to hospital, and then made a spontaneous recovery. Such episodes, formerly often called "near-miss cot deaths", are now usually referred to as ALTEs. At first such attacks were often attributed to some form of respiratory disorder; ${ }^{36}$ 
the phenomenon became the subject of much research, and apnoea monitors were usually provided for the families concerned. In time paediatricians began to realise that a proportion of ALTEs were in fact unnatural, being caused by deliberate obstruction of the airway by the mother, proof sometimes being obtained by covert video surveillance. ${ }^{14}{ }^{18}$ Many of these cases come into the category of fabricated or induced illness by carers (FII), formerly known as Munchausen syndrome by proxy. ${ }^{37}$ In other instances the carer may be driven by a fit of rage or by a misguided attempt to keep the baby quiet. ${ }^{38}$

However assessment of repeat ALTEs, as of repeat deaths, is complicated by the existence of natural conditions that might present in a similar manner, such as respiratory disorders (especially in premature babies), episodic hypoglycaemia, paroxysmal cardiac dysrhythmia, recurrent oesophageal reflux, or epileptic seizures. These should all be carefully considered before a diagnosis of FII can be made with confidence. Samuels et al were able to determine the cause of 77 of 157 cases of ALTE in young children referred to their tertiary centre for investigation between 1986 and 1991: 18 of the $77(23 \%)$ resulted from suffocation while in a further seven $(9 \%)$ the illness was fabricated. ${ }^{39}$

Features taken to be suggestive of suffocation rather than of natural illness include episodes always beginning in the presence of the same person, traces of blood around the infant's mouth or nose, petechiae on the face and throat, and spontaneous recovery. Apart from initial acidosis investigations are often negative. Southall et al have also reported a raised white blood cell count, air leak on chest $x$ ray examination, and hypoxic-ischaemic injury to the brain on computerised tomography. ${ }^{18}$

Limited evidence on the prevalence of ALTE in the general population is provided by the 1299 control infants in the CESDI SUDI study, 39 of whose parents (3\%) said their baby had experienced "an episode in which he or she became lifeless". ${ }^{6}$ It therefore appears that it is not uncommon for parents to report brief episodes of apparent lifelessness in their babies. However more prolonged or repeated attacks merit careful investigation, both for an organic cause and for FII.

\section{Recent medical attention}

SIDS is known to be associated with social disadvantage and with low birth weight, factors that also bring higher infant morbidity, so that SIDS victims might be expected to have received more medical attention than others. However this effect does not appear to be very large, the CESDI SUDI study finding that the proportion of SIDS infants seen by a health professional in the week before death $(57.6 \%)$ was not much higher than that of controls seen in the week before interview $(49.6 \%){ }^{6}$

With regard to hospital admission, 43 (53\%) of Meadow's cases had been patients on children's wards within the previous four weeks, 15 of them (19\%) having been discharged less than 24 hours before they were found dead at home. These surprisingly high figures partly result from the frequency of ALTEs among these babies. A history of frequent previous hospital admission was reported in a study of SIDS victims carried out in the early $1980 \mathrm{~s} ;{ }^{40}$ however it is not clear how carefully covert homicide was excluded in this series. The CESDI SUDI study also found a higher rate of hospital attendance among SIDS babies than among controls. ${ }^{6}$

It therefore appears that while there should be serious concern when a baby dies immediately after being in hospital for investigation of sudden unexplained illness, many genuine SIDS victims have been the recipients of various forms of medical attention.

\section{Characteristics of the parents}

In contrast to recognised homicide, where there is often obvious violence and the perpetrator is usually male, most covert homicides are carried out by the mother. In Meadow's 50 families, 43 mothers and five fathers were incriminated, two cases being uncertain, ${ }^{16}$ while all but three of Southall's 33 cases of abuse involved the mother. ${ }^{18}$ These authors identified a number of other social and personal factors among the parents in their series, including poverty, smoking, a history of impaired parenting or abuse as a child, and personality disorder manifested as self-harm, factitious or psychosomatic illness, or eating problems. Of these factors poverty and smoking also bring added risk for several forms of natural disease and death in infancy, including SIDS, and are therefore of no value as discriminators.

Twenty four of 50 parents (48\%) in Meadow's series and 23 of $39(59 \%)$ in Southall's were assessed as having a personality disorder, a characteristic that has been identified in previous studies of abusing parents. ${ }^{41}$ The definition of personality disorder is imprecise and its prevalence in the general population is unknown, but its frequency in these reports suggests that any unexplained illness or injury in the baby of a parent with a personality disorder should always give rise to concern.

Although no specific mental illness was apparent in the parents in the two main series cited, it has been shown that mothers with schizophrenia or with severe depression are more likely to kill their children; ${ }^{42}$ in some instances such deaths may be classified as infanticide. Maternal depression is also associated with a higher risk of sudden infant death. ${ }^{43}$ It is therefore important to identify and give extra support to depressed mothers, and to intervene quickly if there are concerns about the baby.

\section{DISCUSSION}

It is clear from this survey that our current understanding of covert homicide in infancy is very inadequate. Much better evidence is needed on all aspects: incidence, epidemiological patterns, clinical and pathological features, characteristics, and motivations of perpetrators. Specific needs include clearer profiles of the parents and the babies who are most at risk; sharper distinction between the circumstances that typically surround unnatural as compared with natural deaths; better consensus on the significance of findings such as intracranial haemorrhage, broken ribs, or pulmonary siderophages; identification of accurate pathological markers of suffocation; recognition of all familial disorders that might cause sudden death at this age and development of practical ways to detect them. Scientific studies on these and other issues are urgently needed but will be not be easy because of the infrequency of covert homicide and the uncertainties in its identification. Such studies will require pooling of data from a large population and a comprehensive investigation of every SUDI, including a meticulous history and detailed postmortem examination.

The Foundation for the Study of Deaths, in accord with the recommendations of the CESDI SUDI report, ${ }^{6}$ suggests that the investigation should include three essential components:

(1) A visit to the home by a paediatrician soon after the death to talk with the parents and inspect the scene where the baby died. He/she may visit with a police officer, or if they visit separately they should confer about their impressions. From this visit and from a careful review of all relevant medical and social records the paediatrician should compile a full history, to be made available to the pathologist and coroner.

(2) A postmortem examination carried out by a pathologist with paediatric training following a standard protocol, ${ }^{6}$ 
which should include appropriate tests for familial disorders. If a forensic pathologist is instructed, whenever possible a paediatric pathologist should also participate.

(3) A case discussion, under the auspices of the coroner, between all the professionals involved (including general practitioner, health visitor, pathologist, paediatrician, social worker, police officer) as soon as all the postmortem results are available to consider possible causes of death and contributory factors (and to plan support for the family).

A comprehensive evaluation including the same measures is recommended by the American Academy of Pediatrics. ${ }^{44}$ Thorough investigation of every SUDI in this manner gives the best opportunity of determining a cause of death where this is possible, of recognising the majority of deaths that are natural, and of identifying the minority that result from covert homicide. The current reviews of the coroners' system and of the investigation of deaths in childhood offer an opportunity of introducing measures such as these to ensure that sudden infant deaths are always subject to the most thorough scrutiny.

The present lack of an adequate evidence base is particularly dangerous in an area where wrong diagnosis in either direction can lead to disaster. If covert homicide is missed, another baby may be killed, while false accusation may lead to wrongful imprisonment and destruction of a family. When a baby dies suddenly and unexpectedly it is important that a paediatrician, and wherever possible a paediatric pathologist, should be involved. They are the specialists best equipped to make a diagnosis, and are used to dealing with families and collaborating with other agencies. Giving evidence in court is an integral part of the responsibility, but unfortunately many doctors are put off by the unpleasantness of court appearance and its attendant publicity. The adversarial system of the criminal court is not a suitable forum for the elucidation of complex and sensitive medical problems. The proceedings would be fairer and less contentious-and doctors more likely to come forward-if the reforms recently applied to the use of expert testimony in civil cases were extended to the criminal court. ${ }^{45}$

Professionals who have to deal with SUDI have a highly responsible but very difficult task. They must be alert for the possibility of covert homicide and must try to identify it even though they do not have enough reliable guidance. At the same time they must be careful not to add to the grief of the majority of parents who are innocent through insensitive investigation and unjustified accusation. If called on to given evidence to the police or to the court, they should always be mindful of the limitations of medical knowledge in this area, and of the damage that may ensue from a wrong opinion.

\section{Authors' affiliations}

S Levene, C J Bacon, Foundation for the Study of Infant Deaths, Artillery House, 11-19 Artillery Row, London SW1P 1RT, UK; fsid@sids.org.uk

\section{REFERENCES}

1 Criminal statistics England and Wales, 2000. Stationery Office, December 2001.

2 Marks MN, Kumar R. Infanticide in England and Wales. Med Sci Law 1993:33:329-39.

3 Emery JL. Infanticide, filicide and cot death. Arch Dis Child 1985;60:505-7.

4 Hobbs CJ, Wynne JM. Child abuse and sudden infant death. Child Abuse Review 1996;5:155-69.

5 Emery JL. Child abuse, sudden infant death syndrome, and unexpected infant death. Am J Dis Child 1993;147:1097-100.

6 Fleming P, Blair P, Bacon C, et al. Sudden unexpected deaths in infancy: the CESDI SUDI studies 1993-1996. Stationery Office 2000.
7 Hobbs CJ, Wynne JM, Gelletlie R. Leeds inquiry into infant deaths: the importance of abuse and neglect in sudden infant death. Child Abuse Review 1995:4:329-39.

8 Stanton AN. Sudden unexpected death in infancy associated with maltreatment: evidence from long term follow up of siblings. Arch Dis Child 2003;88:699-701

9 Limerick S, Bacon C. Terminology used by pathologists in reporting on sudden infant deaths. J Clin Pathol 2004;57:309-11.

10 Valdes-Dapena $M$. The sudden infant death syndrome: pathologic findings. Clin Perinat 1992;19:701-16.

11 Becroft DMO, Lockett BK. Intra-alveolar pulmonary siderophages in sudden infant death: a marker for previously imposed suffocation. Pathology 1997;29:60-3.

12 Meadow R. Suffocation, recurrent apnea, and sudden infant death. J Pediatr 1990;117:351-7.

13 Stanton J, Simpson A. Murder misdiagnosed as SIDS: a perpetrator's perspective. Arch Dis Child 2001:85:454-9.

14 Rosen CL, Frost JD, Glaze DG. Child abuse and recurrent apnea. J Pediatr 1986;109:1065-7.

15 Southall DP, Stebbens VA, Rees SV, et al. Apnoeic episodes induced by smothering: two cases identified by covert video surveillance. BMJ 1987;294:1637-41.

16 Meadow R. Unnatural sudden infant death. Arch Dis Child 1999:80:7-14.

17 Mitchell EA. The changing epidemiology of SIDS following the national risk reduction campaigns. Pediatr Pulmonol 1997;16:117-19.

18 Southall DP, Plunkett MCB, Banks MW, et al. Covert video recordings of lifethreatening child abuse: lessons for child protection. Pediatrics 1997; 100:735-60.

19 Limerick SR. Time infant found dead. Newsletter, Foundation for the Study of Infant Deaths 1984;25:3.

20 DiMaio DJ, DiMaio VJM. Forensic pathology. Elsevier, 1989;291.

21 Allison F, Bennett MJ, Variend S. Acyl coenzyme A dehydrogenase deficiency in heart tissue from infants who died unexpectedly with fatty change in the liver. BMJ 1998;296:11-14.

22 Boles GB, Buck EA, Blitzer MG, et al. Retrospective biochemical screening of fatty acid oxidation disorders in postmortem livers of 418 cases of sudden death in the first year of life. J Pediatr 1998;132:924-33.

23 Opdal SH, Vege A, Egeland T, et al. Possible role of m+DNA mutations in sudden infant death. Pediatr Neurol 2002;27:23-9.

24 Schwartz PJ, Stramba-Badiale M, Segantini A, et al. Prolongation of the QT interval and the sudden infant death syndrome. N Engl J Med 1998;338:1707-11.

25 Weese-Mayer DE, Shannon DC, Keens TG, et al. Idiopathic congenital central hypoventilation syndrome: diagnosis and management. Am J Respir Crit Care Med 1999;160:368-73.

26 Weese-Mayer DE, Silvestri JM, Huffman AD, et al. Case/control family study of autonomic nervous system dysfunction in idiopathic congenital central hypoventilation syndrome. Am J Med Genet 2001;100:237-45.

27 Guielleminault C, Heldt G, Powell N, et al. Small upper airway in near-miss sudden infant death syndrome infants and their families. Lancet 1986;1:402.

28 Watkins SJ. Conviction by mathematical error? BMJ 2000;320:2-3.

29 Beal SM, Blundell HK. Recurrence incidence of sudden infant death syndrome. Arch Dis Child 1988;63:924-30.

30 Peterson DR, Sabotta EE, Daling JR. Infant mortality among subsequent siblings of infants who died of sudden infant death syndrome. J Pediatr 1986;108:911-14.

31 Guntheroth WG, Lohmann R, Spiers PS. Risk of sudden infant death syndrome in subsequent siblings. J Pediatr 1990;116:520-4

32 Oyen N, Skjaerven R, Irgens LM. Population-based recurrence risk of sudden infant death syndrome compared with other infant and fetal deaths. Am J Epidemiol 1996;144:300-5

33 Waite A, McKenzie A, Carpenter R, et al. Report on 5000 babies using the CONI (Care of Next Infant) programme. University of Sheffield, 1998.

34 Emery JL. Families in which two or more cot deaths have occurred. Lancet 1986;i:313-15.

35 Wolkind S, Taylor EM, Waite AJ, et al. Recurrence of unexpected infant death. Acta Paediatr 1993;82:873-6.

36 Steinschneider A. Prolonged apnea and the sudden infant death syndrome: clinical and laboratory observations. Pediatrics 1972;50:646-54.

37 Wilson R. Fabricated or induced illness by carers; report of the working party of the Royal College of Paediatrics and Child Health. RCPCH, 2002.

38 Emery JL. Child abuse, sudden infant death syndrome, and unexpected infant death. Am J Dis Child 1993;147:1097-100.

39 Samuels MP, Poets CF, Noyes JP, et al. Diagnosis and management after lifethreatening events in infants and young children who received cardiopulmonary resuscitation. BMJ 1993;306:489-92.

40 Stanton AN, Oakley JR. Pattern of illness before cot deaths. Arch Dis Child 1983;58:1054-7.

41 Oliver JE. Successive generations of child maltreatment: social and medical disorders in the parents. Br J Psychiatry 1985;147:484-90.

42 Davidson J, Robertson E. A follow-up study of post-partum illness. Acta Psych Scand 1985;71:451-7.

43 Sanderson CA, Cowden B, Hall DBM, et al. Is postnatal depression a risk factor for sudden infant death? Br J Gen Pract 2002;52:636-40.

44 American Academy of Pediatrics, Committee on Child Abuse and Neglect. Distinguishing sudden infant death syndrome from child abuse fatalities. Pediatrics 1994;94:124-6.

45 Hey E. Suspected child abuse: the potential for justice to miscarry. BMJ 2003;327:299-300. 